\title{
Selection of Analytical Methods for Mixed Waste Analysis at the Hanford Site
}

Date Published

September 1994

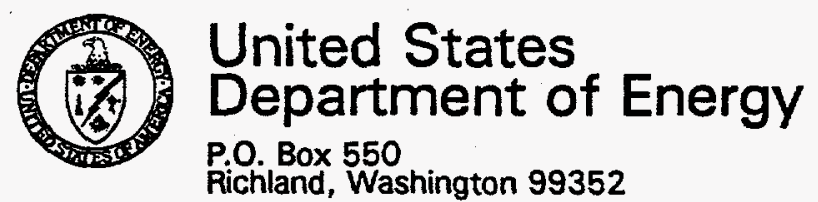

Approved for Public Release 


\section{DISCLAIMER}

This report was prepared as an account of work sponsored by an agency of the United States Government. Neither the United States Government nor any agency thereof, nor any of their employees, make any warranty, express or implied, or assumes any legal liability or responsibility for the accuracy, completeness, or usefulness of any information, apparatus, product, or process disclosed, or represents that its use would not infringe privately owned rights. Reference herein to any specific commercial product, process, or service by trade name, trademark, manufacturer, or otherwise does not necessarily constitute or imply its endorsement, recommendation, or favoring by the United States Government or any agency thereof. The views and opinions of authors expressed herein do not necessarily state or reflect those of the United States Government or any agency thereof. 


\section{DISCLAIMER}

Portions of this document may be illegible in electronic image products. Images are produced from the best available original document. 


\section{Contents}

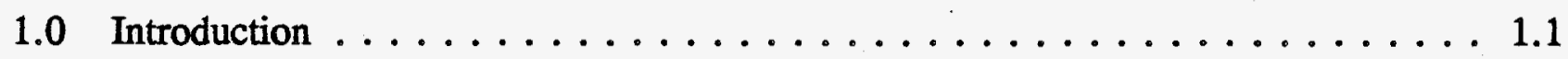

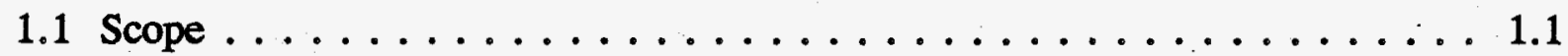

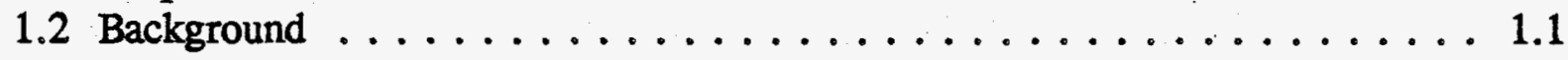

2.0 Regulatory Basis for Method Selection $\ldots \ldots \ldots \ldots \ldots \ldots \ldots \ldots . \ldots \ldots$

2.1 Tri-Party Agreement . . . . . . . . . . . . . . . . 2.1

2.2 DOE Strategy for Compliance $\ldots \ldots \ldots \ldots \ldots \ldots \ldots \ldots \ldots \ldots . \ldots \ldots$

3.0 Restrictions and Limitations On Use of Approved

Analytical Methods . . . . . . . . . . . . . . . 3.1

3.1 Sample Size . . . . . . . . . . . . . . . . . 3.1

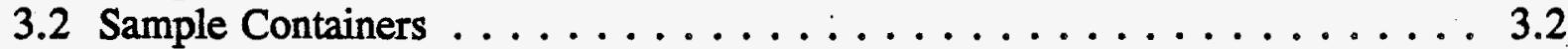

3.3 Sample Preservation . . . . . . . . . . . . . . . . . 3.2

3.4 Quality Control Sample Frequency . . . . . . . . . . . . . . 3.2

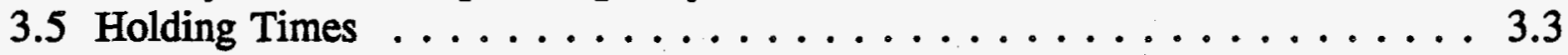

3.6 Alternate/Modified Instrumentation $\ldots \ldots \ldots \ldots \ldots \ldots . \ldots \ldots$

3.7 Chemical Matrix Interferences . . . . . . . . . . . . . . . 3.4

3.8 Disposable Glassware/Plasticware $\ldots \ldots \ldots \ldots \ldots \ldots \ldots . \ldots \ldots$

3.9 Liquid Waste Minimization $\ldots \ldots \ldots \ldots \ldots \ldots \ldots \ldots . \ldots \ldots$

4.0 Data Quality Objective Process and the Hanford

Analytical Services Quality Assurance Plan . . . . . . . . . . . . 4.1

5.0 Documentation and Record Keeping $\ldots \ldots \ldots \ldots \ldots \ldots \ldots \ldots \ldots \ldots$

6.0 References $\ldots \ldots \ldots \ldots \ldots \ldots \ldots \ldots \ldots \ldots \ldots \ldots \ldots \ldots \ldots \ldots$

Appendix

A Waste Analysis Requirements $\ldots \ldots \ldots \ldots \ldots \ldots \ldots \ldots \ldots$. . . . . . 


\section{DOE/RL-94-97}

Revision 0

This page intentionally left blank. 


\section{Selection of Analytical Methods for Mixed Waste Analysis at the Hanford Site}

\subsection{Introduction}

\subsection{Scope}

This document describes the process that the U.S. Department of Energy (DOE), Richland Operations Office (RL) and contractor laboratories use to select appropriate analytical methods for mixed waste analysis or develop new or modified analytical methods. These methods are needed to provide reliable mixed waste characterization data that meet project-specific quality assurance (QA) requirements while also meeting health and safety standards for handling radioactive materials. This process will provide the technical basis for DOE's analysis of mixed waste and support requests for regulatory approval of these new methods when they are used to satisfy the regulatory requirements of the Hanford Federal Facility Agreement and Consent Order (Tri-Party Agreement) (Ecology et al. 1992).

\subsection{Background}

Technical and safety-related issues frequently eliminate the direct application of currently approved regulatory methods to characterize mixed waste at the Hanford facility. The analyses (and related sampling and subsampling procedures) are complicated by the chemical and radioactive nature of the samples. DOE has established a process to provide the flexibility needed to allow easing the laboratories' chemical and radiological interference problems and concurrently operate within the as low as reasonably achievable (ALARA) principle.

The use of new and/or modified methods is consistent with recent joint U.S. Environmental Protection Agency (EPA)/U.S. Nuclear Regulatory Commission (NRC) guidance, Clarification of RCRA Hazardous Waste Testing Requirements for Mixed Waste (EPA and NRC), and the Land Disposal Restrictions "third-third" rule, which emphasizes the EPA's position that permit writers can minimize incremental exposure to chemicals and radiation to provide sampling and analytical flexibility in the waste analysis plans (WAP). It also follows the guidance provided in the August 1993 EPA promulgation of Update I to SW-846 that allows for analyst discretion in making necessary procedural changes to RCRA methods (EPA 1986).

This document presents the details of the procedure that RL is implementing for most current and future waste analysis applications requiring the use of new or modified analytical methods in support of the Tri-Party Agreement (Ecology et al. 1992). The agreement binds $\mathrm{RL}$ to commitments and actions that comply with the Resource, Conservation and Recovery 
Act of 1976 (RCRA), the Comprehensive Environmental Response, Compensation, and Liability Act of 1980 (CERCLA), and the State of Washington Hazardous Waste Management Act of 1976. This paper describes the following:

- Regulatory background for method selection, including mandated use of approved methods

- Restrictions and technical limitations of approved methods for the analysis of mixed waste samples

- Relationship of the Data Quality Objectives (DQO) process and the Hanford Analytical Services Quality Assurance Plan (HASQAP) (DOE-RL 1994) in supporting the use of method deviations

- Documentation of the Hanford Site method development/modification procedure. 


\subsection{Regulatory Basis for Method Selection}

\subsection{Tri-Party Agreement}

The selection of appropriate analytical methods for use in meeting the requirements of the Tri-Party Agreement is guided by the language in Article XXXI, Paragraph 105, which states:

"Throughout all sample collection, preservation, transportation, and analyses activities required to implement this Agreement, DOE shall use procedures for quality assurance, and for quality control, in accordance with approved EPA methods, including subsequent amendments to such procedures. The DOE shall comply with the "Data Quality Strategy for Hanford Site Characterization" (as listed in Appendix F of the Action Plan) and Sections 6.5 and 7.8 of the Action Plan. For special circumstances, other procedures approved by the lead regulatory agency may be used. The DOE shall use methods and analytical protocols for the parameters of concern in the media of interest within detection and quantification limits in accordance with both QA/QC procedures and data quality objectives approved in the work plan, RCRA closure plan or RCRA permit. The EPA or Ecology may require that DOE submit detailed information to demonstrate that any of its laboratories are qualified to conduct the work. The DOE shall assure that EPA and Ecology (including contractor personnel) have access to laboratory personnel, equipment and records related to sample collection, transportation, and analysis."

\subsection{DOE Strategy for Compliance}

Paragraph 105 of Article XXXI sets forth several guidelines that have been incorporated into the Hanford Site approach to selecting appropriate analytical methods. New and modified analytical methods will:

- "Contain quality assurance and quality control procedures consistent with approved methods

- Be submitted to the lead regulatory agency for approval when required under the provisions of the Hanford Dangerous Waste portion or the Federal Hazardous and Solid Waste Amendment portion of the Hanford RCRA Part B Permit

- Analyze parameters of concern in matrices of interest consistent with the needs established by the DQO process and supported by suitable quality assurance/quality control procedures

- Document and make available supporting information demonstrating the technical reliability of the method for its intended application." 
The DOE recognizes that the EPA has established prescriptive requirements methods used for waste designation. In 58 Federal Register (FR) 46040, the Agency states:

"Several of the hazardous waste regulations under Subtitle C of RCRA require that specific testing methods described in SW-846 be employed for certain applications. Any reliable analytical method may be used to meet other requirements in 40 CFR Parts 260 through 270."

Federal regulations mandate use of SW-846 for the following nine specific applications:

40 Code of Federal Regulations (CFR) 260.22(d)(1)(i): Submission of data in support of petitions to exclude a waste produced at a particular facility (i.e., delisting petitions)

- 40 CFR 261.22(a)(1) and (2): Evaluation of waste against the corrosivity characteristic

- 40 CFR 261.24(a): Leaching procedure for evaluation of a waste against the toxicity characteristic

- 40 CFR 264.190(a), 264.314(c), 265.190(a), and 265.314(d): Evaluation of a waste to determine if free liquid is a component of the waste

- 40 CFR 266.112(b)(1): Certain analysis in support of excluding from the definition of a hazardous waste a residue that was derived from burning hazardous waste in boilers and industrial furnaces

- 40 CFR 268.32(i): Evaluation of a waste to determine if it is a liquid for purposes of certain land disposal prohibitions

- 40 CFR 268.40(a), 268.41(a), and 268.43(a): Leaching procedure for evaluating waste extract to determine compliance with land disposal treatment standards

- 40 CFR 270.19(c)(1) (iii) and (iv), and 270.62(b)(2)(i) (C) and (D): Analysis and approximate quantification of the hazardous constituents identified in the waste before conducting a trial burn in support of an application for a hazardous waste incineration permit

40 CFR 270.22(a)(2)(ii)(B) and 270.66(c)(2) (i) and (ii): Analysis conducted in support of a destruction-and-removal-efficiency trial burn waiver for boilers and industrial furnaces burning low-risk waste, and analysis and approximate quantitation conducted for a trial burn in support of an application for a permit to burn hazardous waste in a boiler and industrial furnace. 
For the circumstances described in these nine citations, DOE intends to follow the prescribed methods or seek formal approval of modifications or alternative methods. DOE expects that the lead regulators will need to be approached on a case-by-case basis in each of these nine circumstances as the situation warrants and has been done in the past. The EPA has already recognized that certain adjustments may have to be made in specific instances. In a letter to RL (EPA 1993), the EPA indicates that the toxicity characteristic leaching procedure (TCLP) sample size is a recommended size and that smaller sample sizes can be used subject to certain restrictions.

For circumstances other than those described in the nine citations, DOE intends to apply the principles established in this document, to all other analysis requirements at the Hanford Site not specifically noted above. Appendix A discusses the basis for and the process that will be followed in selecting an analytical method as it applies to the various operating units under different regulatory scenarios. This appendix also addresses the requirements of both the EPA and the U.S. Department of Ecology (Ecology). 
This page intentionally left blank. 


\subsection{Restrictions and Limitations On Use of Approved Analytical Methods}

Many of the restrictions and limitations on the choice of analytical methods begin when the sample is collected in the field and continue through the analytical process all the way to laboratory waste disposal. Some reasons for this are:

- Safety related, based on the ALARA principle to ensure minimal exposure of staff to radiation

- Logistical, related to the safe handling of nuclear material

- Chemical, related to the unusual nature of Hanford Site waste matrices.

Most of these reasons are well understood and can be anticipated before work begins. Therefore, project personnel and regulatory oversight staff will be able to discuss issues in the DQO process and the resulting solutions/alternatives will be approved before beginning work.

The primary reasons are discussed in the following paragraphs, which are arranged in the sample's life-cycle sequence, beginning with its collection.

\subsection{Sample Size}

Sample size is restricted by the limitations of sample retrieval equipment and the large, heavily shielded casks needed for storage and transportation. Therefore a limited sample is used for performing all required analyses. The unique nature of the materials contained in single-shell tanks (e.g., crust formation, void volumes caused by gas accumulation, presence of unconsolidated material and slurries) make efficient sample retrieval difficult. When multiple analytical determinations are required, the sample size limited each test.

This limitation may result in using smaller sample volumes and/or masses than were called for in the original method in the analytical protocol. This will reduce overall method sensitivity by an amount equal to the relative percent decrease in sample if the reagent volumes are not decreased a corresponding amount. Limited sample size may also limit the use of that sample in routine $\mathrm{QA} /$ quality control $(\mathrm{QC})$ protocols requiring multiple aliquots of the sample material, e.g., laboratory duplicates, matrix spikes, and matrix spike duplicates. Where circumstances influence the data requirements identified in the DQO process, they will be explained in the case narrative accompanying the analytical report. Data validation protocols will be adjusted to prevent rejection of data when this occurs. 


\subsection{Sample Containers}

Glass containers with Teflon ${ }^{1}$-lined septums or caps are required for most organic analyses, and zero headspace is required for volatile organic analysis per SW-846 methods. However, the high radiation level of much of the waste on the Hanford Site often makes remote handling necessary and zero headspace sampling impractical and nearly impossible. The headspace is minimized as much as remote manipulation will allow.

These circumstances require that the normally accepted practice of rejecting sample analysis data because of the presence of headspace will be changed. When headspace is observed in a sample, the information will be duly noted in the analytical report but the data will not be rejected as unusable by the data validation process. This limitation will not affect nonradioactive samples and they will be handled, analyzed, and validated using standard $\mathrm{QA} / \mathrm{QC}$ procedures.

\subsection{Sample Preservation}

Most approved methods, including SW-846, require samples to be cooled to $4{ }^{\circ} \mathrm{C}$ while awaiting analysis. Because of high radioactivity, Tank Waste Remediation System (TWRS) samples must be transported and stored in shielded casks, which precludes sample cooling. In addition, some of the waste inherently generates heat and cannot be cooled to the required temperature without extreme measures being taken.

Liquid samples require acidification to $\mathrm{pH} 2$ for preservation before most metal analyses. The high radiation levels for many of the samples on the Hanford Site will require that different procedures be used. Many samples (especially single-shell waste tank samples) will be collected and shipped in special vessels that cannot be accessed to adjust the $\mathrm{pH}$. In these cases, the presence of liquid materials will not be known until the sample is extruded from the sample core collection barrel.

Appropriate changes in the data validation protocols will be implemented. Nonradioactive samples will not be affected and standard QA/QC conditions will apply.

\subsection{Quality Control Sample Frequency}

Most approved analytical methods require that a number of $\mathrm{QC}$ samples related to sampling be initiated in the field. One field duplicate and equipment rinsate sample per day per matrix is required. Trip blanks are required for each day for volatile organic analysis.

${ }^{1}$ Teflon is a trademark of E.I. duPont de Nemours \& Co. 
In addition, enough sample must be collected for one sample per batch (not to exceed 20 samples) of one matrix so that a matrix spike, a matrix duplicate, or matrix spike duplicate can be performed in the laboratory.

Requirements for trip blanks do not pose any specific problems. However, obtaining equipment rinsate samples can be difficult when remote manipulation of sampling equipment is required. The requirement to collect extra sample material for field duplicates, matrix spikes, and matrix spike duplicates often can be met, but may work against ALARA principles for limiting radiation exposure.

QA/QC reporting requirements and data validation protocols will be changed to reflect these limitations, and the case narrative will explain the absence of routine QA/QC samples related to field collection.

\subsection{Holding Times}

Regulatory holding time criteria range from 24 to 48 hours for some inorganic tests, to 1 to 2 weeks for most organic analyses, and up to 6 months for most metals and radionuclides. The shorter holding times required for some tests will frequently not be met because of the increased time required to handle high radiation samples with remote handlers in hot cells. The increased logistics required to survey, transport, and screen the samples before analysis will also increase the time between sample collection and analysis.

\subsection{Alternate/Modified Instrumentation}

High radioactivity can limit types of instrumentation and/or require alternative or modified instrumentation to reduce dose rate (time of exposure, distance to exposure) for the analysts at the laboratory bench. For example, atomic absorption spectroscopy, inductively coupled plasma emission spectroscopy, ion chromatography, and chromatography instrumentation must be modified to allow the capture of all gas or waste discharges. This typically means physical modification to allow gas collection/capture in a hood.

The high radiation level of samples has also caused the Hanford Site laboratories to adopt the use of ion chromatography instead of individual wet-chemical techniques for nitrate, nitrite, chloride, fluoride, and sulfate. Ion chromatography requires much smaller sample volumes. These types of procedures generally do not cause any loss of sensitivity or precision or increase in bias. This is also the primary reason that Hanford Site laboratories are moving to micro- and mini-distillation/digestion techniques.

These procedural changes and resulting QA/QC protocols are described in the HASQAP, Section 8.0. 


\subsection{Chemical Matrix Interferences}

In some cases, it is not the radioactivity of the material that causes analytical problems, but rather the chemical matrix itself. For many wastes, high ionic concentrations diminish the technical reliability of methodology designed to measure trace-level contaminants.

Specific chemical environments exist within the TWRS tanks and their samples that prevent the use of certain methods or portions of methods. For example, high nitrate concentrations within some tank waste are incompatible with SW-846 method 8270 for semivolatile organics because of the chemical reaction (nitration) of the surrogates. Appropriate modifications will be made to generate reliable analytical results.

Suitable new or modified methods will be used consistent with the procedures described in the HASQAP, Section 8.0.

\subsection{Disposable Glassware/Plasticware}

Performing effective glassware decontamination without exposing personnel to unnecessary radiation doses during glassware collection, storage, and cleaning is troublesome and potentially dangerous. Therefore, disposable alternatives are aggressively pursued. To minimize total waste volume, disposable glassware should be as compact and efficient as possible.

\subsection{Liquid Waste Minimization}

Minimizing mixed waste at the laboratory is a strong driver toward lower sample volumes and more efficient use of the samples and their associated preparative and determinative techniques. For example, it is unwise for a laboratory to generate a liter of TCLP leachate when analytical requirements may only use 1 to $200 \mathrm{~mL}$. The unused portion must be disposed of as mixed waste. All reagents/solvents used in the laboratory are more difficult to dispose of when radioactivity is also a concern because of the mixed-waste generation issue. Any changes made to use smaller analytical samples will be addressed as described earlier. 


\subsection{Data Quality Objective Process and the Hanford Analytical Services Quality Assurance Plan}

The majority of work conducted at the Hanford Site will be planned and executed using the DQO planning process. This will enable project personnel to anticipate most analytical problems and address them in planning meetings. A consensus solution will be reached and any resulting work plans will be approved through the normal process. All work will be conducted under the agreed-to analytical procedures and accompanying QA/QC protocols.

RL is implementing a sitewide quality assurance plan (HASQAP) to guide all analytical services covered by the Tri-Party Agreement. The HASQAP provides detailed procedures for qualification and documentation of any modified or new methods (Section 8.0). Inputs from the EPA and Ecology will be sought before the HASQAP is fully implemented (August 31, 1995). 
This page intentionally left blank. 


\subsection{Documentation and Record Keeping}

All documentation relating to deviations will be maintained as part of the analytical record and report with full explanation in the case narrative. Data validators will be notified in advance if special data validation protocols are to be used when evaluating the results.

All studies relating to the evaluation and qualification of new or modified methods, per Section 8.0 of the HASQAP, will be retained as part of the permanent laboratory record accompanying the laboratory procedure. A notice of the adoption of a new or modified method will be made to clients if the changes occur for work in progress. For new work, the method will be proposed as part of the DQO planning activity. Copies of the laboratory procedures and supporting laboratory data will be made available to regulatory officials on request. 


\section{DOE/RL-94-97}

Revision 0

This page intentionally left blank. 


\subsection{References}

40 CFR 260, "Hazardous Waste Management System-General," Code of Federal Regulations, as amended.

40 CFR 261, "Identification and Listing of Hazardous Waste," Code of Federal Regulations, as amended.

40 CFR 264, "Standards for Owners and Operators of Hazardous Waste Treatment, Storage, and Disposal Facilities," Code of Federal Regulations, as amended.

40 CFR 266, "Standards for the Management of Specific Hazardous Wastes and Specific Hazardous Waste Management Facilities," Code of Federal Regulations, as amended.

40 CFR 268, "Land Disposal Restrictions," Code of Federal Regulations, as amended.

40 CFR 270, "EPA Administered Permit Programs: The Hazardous Waste Permit Program," Code of Federal Regulations, as amended.

58.FR 46040, "Hazardous Waste Management System; Testing and Monitoring Activities," Federal Register.

Comprehensive Environmental Response, Compensation, and Liability Act of 1980, 42 USC 9601 et seq.

DOE-RL, 1994, Hanford Analytical Services Quality Assurance Plan, DOE/RL-94-55, Rev. 0, U.S. Department of Energy, Richland Operations Office, Richland, Washington.

Ecology, EPA, and DOE, 1992, Hanford Federal Facility Agreement and Consent Order, 2 vols, as amended, Washington State Department of Ecology, U.S. Environmental Protection Agency, and U.S. Department of Energy, Olympia, Washington.

EPA, 1986, Test Methods for the Evaluation of Solid Waste, Physical/Chemical Methods, SW-846, 3rd ed., U.S. Environmental Protection Agency, Washington, D.C.

EPA, 1993, "Application of the Toxic Characteristic Leach Procedure Extractions for Metals to Grouts," (external letter to U.S. Department of Energy, Richland Operations Office, dated June 11), U.S. Environmental Protection Agency, Region 10, Olympia, Washington.

EPA and NRC, Clarification of RCRA Hazardous Waste Testing Requirements for Mixed Waste, U.S. Environmental Protection Agency and U.S. Nuclear Regulatory Commission, Washington, D.C. 
Resource Conservation and Recovery Act of 1976, 42 USC 6901 et seq.

"State of Washington Hazardous Waste Management Act of 1976," Revised Code of

Washington, Chapter 70.105 et seq., Olympia, Washington. 


\section{Appendix A}

Waste Analysis Requirements 
This page intentionally left blank. 


\section{Appendix A}

\section{Waste Analysis Requirements}

\section{A1.0 General Waste Analysis Requirements}

General waste analysis requirements are found in the federal regulations of 40 Code of Federal Regulations (CFR) 265.13 for interim status facilities and 40 CFR 264.13 for final status facilities. Corresponding regulations for Washington State are found in Washington Administrative Code (WAC) 173-303-300. The Washington State Department of Ecology (Ecology) has been delegated authority by the U.S. Environmental Protection Agency (EPA) to implement their own Resource Conservation and Recovery Act of 1976 (RCRA) program in lieu of the federal program. Therefore, use of WAC 173-303-300 is appropriate for determining most Hanford facility waste analysis requirements. However, because Ecology has not been delegated authority to implement the Hazardous and Solid Waste Amendments of 1984 (HSWA), waste analysis requirements for compliance with land disposal restrictions (LDR) still must be administered pursuant to the federal regulations of 40 CFR 268 . Consequently, although WAC 173-303-300 is applicable for non-LDR waste analysis requirements, 40 CFR 268 is still applicable for LDR requirements until the EPA delegates HSWA authority to Ecology.

The WAC 173-303-300 provisions require the owner/operator of a treatment, storage, and/or disposal (TSD) facility to obtain a detailed chemical, physical, and/or biological analysis of dangerous waste before TSD. Furthermore, this regulation indicates that the analysis can include or consist of existing published or documented data on the dangerous waste, data on waste generated from similar processes, or on data obtained by testing if necessary. Note that the word 'analysis' is used to encompass all information used to confirm knowledge concerning the waste. Analysis in this context is not directly translated to require laboratory testing, but as WAC 173-303-300 indicates, analysis includes both the use of existing published or documented data and testing.

The WAC 173-303-300 requirements also mandate the development of a written waste analysis plan that describes the procedures that will be used to obtain the required analyses. The waste analysis plan must address each dangerous waste that will be analyzed. The WAC 173-303-300(5) requirements contain the minimum elements required in a TSD facility waste analysis plan and include the following:

- Parameters for which each dangerous waste will be analyzed and the rationale for selecting these parameters

- Methods of obtaining or testing for these parameters 
- Methods for obtaining representative samples of waste for analysis

- Frequency with which analysis of a waste will be reviewed or repeated to ensure that the analysis is accurate and current

- Waste analyses that generators have agreed to supply

- Where applicable, methods for meeting the additional waste analysis requirements for specific waste management methods as specified in the interim status regulations for interim status facilities and in the final status regulations for final status facilities

- For offsite facilities, the procedures for confirming that each dangerous waste received matches the identity of the waste specified on the accompanying manifest or shipping paper, including procedures for identifying each waste movement at the offsite facility and the method for obtaining a representative sample of the waste if the identification method includes sampling.

The plan must identify the methods of testing that will be employed for facets of the waste analysis plan entailing testing. The WAC 173-303-300(5)(b) requirement does not mandate the use of WAC 173-303-110 requirements or SW-846 (EPA 1986) procedures for testing. However, the sampling requirement of WAC 173-303-300(5)(c) does cite WAC 173-303-110(2) requirement for discussion on representative sampling.

The WAC 173-303-110 requirement contains information on testing methods that can be used for the purpose of designating a dangerous waste. Waste designation is addressed in Section A2.0. As stated previously, the WAC 173-303-300(5)(c) requirement references the WAC 173-303-110(2) requirement, which states that Ecology will consider samples collected in accordance with WAC 173-303-110(2) to be representative. The EPA indicates in 40 CFR 264.13 and 40 CFR 265.13 that representative sampling can be obtained one of two ways: (1) by using one of the sampling methods described in Appendix I of 40 CFR 261, or (2) by using an 'equivalent sampling method.' The methods of the referenced Appendix I are identical to those found in the WAC 173-303-110(2) requirement.

Stipulations concerning the concept of equivalent sampling methods for the purpose of obtaining representative samples do not exist in the WAC 173-303-110 requirement. However, the federal regulations for waste analysis contain comments referencing petitioning regulations following the subsections on representative sampling. The interim status sampling regulation [40 CFR 265.13(b)(3)] is followed by a comment reference to 40 CFR 260.20 (c). The final status sampling regulation [40 CFR 264.13(b)(3)] is followed by a comment reference to 40 CFR 260.21. Both 40 CFR 260.20 and 40 CFR 260.21 contain provisions for general rule making petitions and petitions for the addition of equivalent testing and analytical methods to the regulations, respectively. Confusion may occur when attempting to decipher this information, because those comments referencing 40 CFR 260 follow the provisions for sampling, whereas the information referenced in the final status regulation pertains to testing and analytical methods. 
As stated previously, the WAC 173-303-110 requirements exist to describe methods that can be used for designating dangerous waste. There are no references in the WAC 173-303-300 requirement that mandate use of the WAC 173-303-110 requirements for TSD facility waste analysis. The WAC 173-303-110(5) requirement does indicate that requests can be made for approval of equivalent designation testing methods through petition submittal. In requesting equivalent testing, petitions must be prepared and submitted to Ecology in accordance with the WAC 173-303-910(2) requirement. The WAC 173-303-910 requirement exist for the purpose of amending regulations, not for the purpose of amending a facility's internal procedures. The process in the WAC 173-303-910(2) requirement is employed when anyone wishes to add a testing or analytical method to the regulation of WAC 173-303-110.

For equivalent sampling, there are no specific provisions in either the federal or state regulations that address petitions for equivalent sampling. As stated, the WAC 173-303-910(2) requirement provides petitioning requirements to add testing or analytical methods to the regulations. Nevertheless, petitions to add equivalent sampling methods to the regulations are not precluded. The WAC 173-303-910(1) requirement provides for general petitions by which modification of any provision of WAC 173-303 can be proposed. For the concept of representative sampling, the EPA states in 45 FR 33069 that a representative sample must "exhibit the average properties of the universe or whole." Additionally, SW-846 provides detailed information on representative sampling procedures and sampling strategies.

In summary, regulations for waste analysis should not be confused with regulations for designation. Neither federal nor state regulations for waste analysis mandate use of specific testing and analytical procedures such as SW-846. It does not appear that the specific sampling methods of WAC 173-303-110 are mandated by regulation. Nevertheless, TSD facility waste analysis that is performed in accordance with the procedures identified in WAC 173-303-110(3) most likely will satisfy regulator sensitivity, accuracy, and precision objectives. 
This page intentionally left blank. 


\section{A2.0 Waste Designation Requirements}

As stated previously, designation differs from confirmation. The owner/operator of a TSD facility is required to confirm their knowledge concerning the waste they manage. Generators are required to perform dangerous waste designations for the solid waste that they generate. In 58 FR 46040, the EPA states: "Several of the hazardous waste regulations under Subtitle C of RCRA require that specific testing methods described in SW-846 be employed for certain applications. Any reliable analytical method may be used to meet other requirements in 40 CFR Parts 260 through 270." Federal regulations that mandate use of SW-846 are as follows:

- 40 CFR 260.22(d)(1)(i): Submission of data in support of petitions to exclude a waste produced at a particular facility (i.e., delisting petitions)

- 40 CFR 261.22(a)(1) and (2): Evaluation of waste against the corrosivity characteristic

- 40 CFR 261.24(a): Leaching procedure for evaluation of a waste against the toxicity characteristic

- 40 CFR 264.190(a), 264.314(c), 265.190(a), and 265.314(d): Evaluation of a waste to determine if free liquid is a component of the waste

- 40 CFR 266.112(b)(1): Certain analysis in support of exclusion from the definition of a hazardous waste of a residue which was derived from burning hazardous waste in boilers and industrial furnaces

- 40 CFR 268.32(i): Evaluation of a waste to determine if it is a liquid for purposes of certain land disposal prohibitions

- 40 CFR 268.40(a), 268.41(a), and 268.43(a): Leaching procedure for evaluation of waste extract to determine compliance with land disposal treatment standards

- 40 CFR 270.19(c)(1)(iii) and (iv), and 270.62(b)(2)(i)(C) and (D): Analysis and approximate quantification of the hazardous constituents identified in the waste before conducting a trial burn in support of an application for a hazardous waste incineration permit

- 40 CFR 270.22(a)(2)(ii)(B) and 270.66(c)(2)(i) and (ii): Analysis conducted in support of a destruction and removal efficiency trial burn waiver for boilers and industrial furnaces burning low-risk wastes, and analysis and approximate quantitation conducted for a trial burn in support of an application for a permit to burn hazardous waste in a boiler and industrial furnace. 
The federal regulations pertaining to waste designation are clear on the use of SW-846. The EPA mandates use of SW-846 only under certain testing circumstances as addressed previously. The EPA recognizes that for some of these testing circumstances, the specific situation might require latitude with respect to the actual implementation of the SW-846 requirement. For example, in a letter from the EPA Region 10 to the U.S. Department of Energy (DOE), Richland Operations Office (RL), dated June 11, 1993, the EPA indicates that the toxicity characteristic leaching procedure (TCLP) sample size is a recommended sample size and that smaller sample sizes can be used subject to certain restrictions.

In Washington State, the designation process entails examination of the waste in accordance with the regulations found in WAC 173-303-070 (because Washington State has been empowered to operate their own RCRA-based program in lieu of the federal program). The existing regulation in WAC 173-303-070 appears to mandate the use of WAC 173-303-110 requirements for designation testing only in situations where process knowledge is insufficient for proper designation. In Washington State Register 93-12-109, Ecology proposed adding a new subsection WAC 173-303-070(3)(c), which was ultimately issued in the "Dangerous Waste Regulations" on December 8, 1993, to read as follows:

"(c) For the purpose of determining if a solid waste is a dangerous waste as identified in WAC 173-303-080 through 173-303-100, a person shall either

(i) Test the waste according to the methods, or an approved equivalent method, set forth in WAC 173-303-110; or

(ii) Apply knowledge of the waste in light of the materials or the process used, when

(A) Such knowledge can be demonstrated to be sufficient for determining whether or not it designated and/or designated properly; and

(B) All data and records supporting this determination in accordance with WAC 173-303-210(3) are retained on-site."

In the Washington State Register 93-12-109 preamble discussion, Ecology indicated that this section was being added to "clarify the steps a person must take to designate a solid waste." In commenting, RL expressed concern regarding an implied mandate that only specific test methods be used to designate a waste. Additionally, RL commented that the 
EPA mandates use of SW-846 only in specific situations. Ecology responded to the concern over the implied mandate as follows:

"While in some circumstances it is appropriate that waste sampling and testing be performed in strict accordance with the methods described in WAC 173-303-110, in many situations a less rigorous sampling and testing approach is suitable. This less rigorous approach would be considered to be the basis for a generator's knowledge of the waste, as long as the data and other information would be sufficient to determine whether or not a waste is designated and/or designated properly."

The WAC 173-303-090(3) requirement states that "the testing methods specified in this section shall be the only acceptable methods, unless the department approves an equivalent test method in accordance with WAC 173-303-910(2)." This language is explicit concerning testing methods for generator use in testing for determination of dangerous waste characteristics, pursuant to WAC 173-303-070(3)(c)(i). However, when process knowledge is employed pursuant to WAC 173-303-070(3)(c)(ii), a less rigorous sampling and analysis approach may be suitable.

Examples of methods mandated for testing are as follows.

- Characteristic of ignitability: American Society for Testing and Materials (ASTM) Standard D-93-79, D-93-80, or D-3278-78

- Characteristic of corrosivity: Method 5.2 in EPA (1986) (Aqueous)

- Characteristic of corrosivity: NACE Standard TM-01-69 as standardized in EPA (1986) (Nonaqueous liquid)

- Characteristic of corrosivity: Test procedures of WAC 173-303-110(3)(a) (Solid or semisolid mixed)

- Characteristic of reactivity: No specific test method referenced

- Characteristic of toxicity: TCLP found in Appendix II of 40 CFR 261 or equivalent methods approved under the WAC 173-303-110(5) requirement. 
This page intentionally left blank. 


\section{A3.0 Guidance Documents}

There is guidance provided by the U.S. Environmental Protection Agency. According to the most recent guidance document (Draft OSWER 9938.4-03, EPA [1992]) made available by the EPA, there are two basic categories of waste analysis options under RCRA. The document identifies the preferred method as sampling and laboratory analysis because it is more accurate and defensible than other options. A TSD facility also may use acceptable knowledge to meet all or part of the waste analysis requirements.

When employing sampling and laboratory analysis, a TSD waste analysis plan must employ testing and analytical methods that are capable of providing reliable data to ensure safe and effective waste management. Factors, e.g., the physical state of the waste, the analytes of concern, the required detection limits, and the information requirements, will be critical for determination of the appropriate methodology for a given effort.

Acceptable knowledge includes the following:

- Process knowledge consists of detailed information on waste that has been obtained from published or documented waste analysis data or studies conducted on hazardous waste generated by processes similar to that which generated the waste.

- Waste analysis data consist of information from TSD facilities sending waste offsite for TSD.

- The TSD facility's records of analysis performed before the effective date of RCRA regulations must ensure that such information is current and accurate.

In situations where acceptable knowledge is used, proper documentation is essential. Regulators who are engaged in enforcement actions typically will look for documentation that presents clearly that the information used is sufficient to identify the waste accurately and completely. Additionally, when employing either acceptable knowledge or laboratory analysis, proper documentation is essential for identification of constituents that are subject to land disposal restriction standards.

When relying on acceptable knowledge for proper waste management, consideration should be given to various factors, including the following:

- Any differences between the generating process and the process used in relied-upon published or documented data

- How regulatory changes since the study could affect the currency of the study used (e.g., extraction procedure toxicity versus TCLP, increased number of constituents regulated)

- Integrity of data supplied by generators 
- Ability to demonstrate compliance with land disposal restriction requirements

- Periodic review of data to ensure regulatory changes are integrated

- Current state of analytical techniques that might have been relied on in documented - studies.

For detailed guidance on development of waste analysis plans, refer to Draft OSWER 9938.4-03 (EPA 1992).

Additionally, the EPA addressed waste analysis in Chapter 5.0 of Permit Applicants' Guidance Manual for the General Facility Standards of 40 CFR 264 (EPA 1983). This document also provides guidance in Section 5.3.3 for the development of waste analysis plans. 


\section{A4.0 Data Quality Objectives}

As previously stated, waste analysis plans are required by WAC 173-303-300 requirement to contain information on "the parameters for which each dangerous waste will be analyzed, and the rationale for selecting these parameters." In identifying the rationale for selection of parameters, a waste analysis plan should give indication of how analysis for the parameter(s) will provide sufficient information on the waste's properties to meet the

WAC 173-303-300-1 requirement. The methods of obtaining parameters and the methods used for testing should be determined through the parameter selection process. On the Hanford Site, each sampling effort performed pursuant to a waste analysis plan has been agreed to be established through a data quality objective (DQO) approach as required by the Hanford Federal Facility Agreement and Consent Order (Tri-Party Agreement), Section 6.5, Action Plan (Ecology et al. 1994). Use of the DQO process should result in identification of the appropriate parameters for testing and, where appropriate, testing methods should be drawn from SW-846 based upon the DOOs.

The Tri-Party Agreement Paragraph 94, reads as follows:

"Throughout all sample collection, preservation, transportation, and analyses activities required to implement this Agreement, DOE shall use procedures for quality assurance, and for quality control, in accordance with approved EPA methods, including subsequent amendments to such procedures. The DOE shall comply with the "Data Quality Strategy for Hanford Site Characterization" (as listed in Appendix F of the Action Plan) and Sections 6.5 and 7.8 of the Action Plan. For special circumstances, other procedures approved by the lead regulatory agency may be used. The DOE shall use methods and analytical protocols for the parameters of concern in the media of interest within detection and quantification limits in accordance with both QA/QC procedures and data quality objectives approved in the work plan, RCRA closure plan or RCRA permit. The EPA or Ecology may require that DOE submit detailed information to demonstrate that any of its laboratories are qualified to conduct the work. The DOE shall assure that EPA and Ecology (including contractor personnel) have access to laboratory personnel, equipment and records related to sample collection, transportation, and analysis."

The Tri-Party Agreement Action Plan, Section 6.5, reads as follows:

"The level of quality assurance and quality control (QA/QC) for the collection, preservation, transportation, and analysis of each sample which is required for implementation of this Agreement shall be dependent upon the data quality objectives for the sample. Such data quality objectives shall be specified in RCRA closure plans, the RCRA permit, and any other relevant plans that may be used to describe sampling and analyses at RCRA TSD units."

"The QA/QC requirements shall range from those necessary for non-laboratory field screening activities to those necessary to support a comprehensive laboratory analysis 
that will be used in final decision-making. This range of $Q A / Q C$ options is included in the "Data Quality Strategy for Hanford Site Characterization" (as listed in Appendix F). This document is subject to approval by EPA and Ecology.

Based on the data quality objectives, the DOE shall comply with EPA guidance documents for QA/QC and sampling and analysis activities which are taken to implement the Agreement. Such guidance includes the following:

- Guidelines and Specifications for Preparing Quality Assurance Program Plans (QAMS-004/80) (EPA 1980a)

- Interim Guidance and Specifications for Preparing Quality.Assurance Project Plans (QAMS-005/80) (EPA 1980b)

- Data Quality Objectives for Remedial Response Activities (EPA/540/G-87/003 and EPA/540-G-87/004) (EPA 1987a)

- Test Methods for the Evaluation of Solid Waste: Physical/Chemical Methods (EPA/SW-846) (EPA 1987c).

In some instances, RCRA TSD units are included in operable units and are scheduled for investigation and closure as part of the operable unit remedial action. DOE shall follow the provisions of Section 7.8 for QA/QC for sampling and analysis activities at these land disposal units.

In regard to $\mathrm{QA}$ requirements for construction of RCRA land disposal facilities, DOE shall comply with Technical Guidance Document: Construction Quality Assurance for Land Disposal Facilities (EPA 1987b).

For analytical chemistry and radiological laboratories, the QA/QC plans must include the elements listed in "Guidance on Preparation of Laboratory Quality Assurance Plans" (as listed in Appendix F). DOE shall submit laboratory QA/QC plans to EPA and Ecology for review as secondary documents prior to use of that laboratory. In the event that DOE fails to demonstrate to the lead regulatory agency that data generated pursuant to this Agreement was obtained in accordance with the QA/QC requirements of this section, including laboratory QA/QC plans, DOE shall repeat sampling or analysis as required by the lead regulatory agency. Such action by the lead regulatory agency shall not preclude any other action which may be taken pursuant to this Agreement. For other data, Ecology or EPA may request DOE to provide QA/QC documentation. Any such data that does not meet the QA/QC standard required by this section shall be clearly flagged and noted to indicate this fact." 


\section{A5.0 References}

40 CFR 260, "Hazardous Waste Management System-General," Code of Federal Regulations, as amended.

40 CFR 261, "Identification and Listing of Hazardous Waste," Code of Federal Regulations, as amended.

40 CFR 264, "Standards for Owners and Operators of Hazardous Waste Treatment; Storage, and Disposal Facilities," Code of Federal Regulations, as amended.

40 CFR 265, "Interim Status Standards for Owners and Operators of Hazardous Waste Treatment, Storage, and Disposal Facilities, " Code of Federal Regulations, as amended.

40 CFR 268, "Land Disposal Restrictions," Code of Federal Regulations, as amended.

45 FR 33069, "Definition of Representative Sample," Federal Register, as amended.

58 FR 46040, "Hazardous Waste Management System; Testing and Monitoring Activities," Federal Register, as amended.

ASTM, 1990, Annual Book of ASTM Standards, American Society for Testing and Materials, Philadelphia, Pennsylvania.

Ecology, EPA, and DOE, 1994, Hanford Federal Facility Agreement and Consent Order, 2 vols., as amended, Washington State Department of Ecology, U.S. Environmental Protection Agency, and U.S. Department of Energy, Olympia, Washington.

EPA, 1980a, Guidelines and Specifications for Preparing Quality Assurance Program Plans, QAMS-004/80, U.S. Environmental Protection Agency, Washington, D.C.

EPA, 1980b, Interim Guidance and Specifications for Preparing Quality Assurance Project Plans, QAMS-005/80, U.S. Environmental Protection Agency, Washington, D.C.

EPA, 1986, Test Methods for the Evaluation of Solid Waste: Physical/Chemical Methods, SW-846, 3rd ed., U.S. Environmental Protection Agency, Washington, D.C.

EPA, 1987a, Data Quality Objectives for Remedial Response Activities, EPA/540/G-87/003 and EPA/540-G-87/004, U.S. Environmental Protection Agency, Washington, D.C.

EPA, 1987b, Technical Guidance Document: Construction Quality Assurance for Land Disposal Facilities, EPA/530-SW-86-031, U.S. Environmental Protection Agency, Washington, D.C. 
EPA, 1987c, Test Methods for the Evaluation of Solid Waste: Physical/Chemical Methods, SW-846, U.S. Environmental Protection Agency, Washington, D.C.

EPA, 1992, Draft Waste Analyses Plan Guidance Manual, Draft OSWER Directive 9938.4-03, U.S. Environmental Protection Agency, Washington, D.C.

EPA, 1993, "Application of the Toxic Characteristic Leach Procedure Extractions for Metals to Grouts," (external letter to U.S. Department of Energy, Richland Operations Office, dated June 11), U.S. Environmental Protection Agency, Region 10, Olympia, Washington.

Hazardous and Solid Waste Amendments of 1984, 42 USC 6912(a), 6921, 6922, 6924, 6925, 6926, 6930, 6935, 6937, 6939, 6991, and 6993.

WAC 173-303, "Dangerous Waste Regulations," Washington Administrative Code, as amended. 


\section{Distribution}

No. of

Copies

ONSITE

27

U.S. Department of Energy, Richland Operations Office
A. V. Beard
S7-55
G. M. Bell
C. J. Bosted
M. L. Burrell
R. P. Carter
C. E. Clark
J. M. Clark
C. Colantes
J. W. Day
J. K. Erickson
M. J. Furman
R. E. Gerton
E. D. Goller
J. D. Goodenough
R. F. Guercia
C. K. Kasch
P. W. Krueger
C. K. Liu
J. R. Noble-Dial
T. G. Provost
J. E. Rasmussen
C. R. Richins
A. D. Scrantz
R. K. Stewart
T. M. Stram
D. M. Wanek
Reading Room
A5-52
A5-52
R3-80
S7-55
A5-15
S7-54
L4-40
A5-19
A5-19
R3-81
S7-54
A5-19
A5-19
S7-55
A5-55
K8-50
A5-52
S7-54
L4-40
A5-15
L4-40
R3-80
A5-19
S7-55
A5-19
H2-53

11 Bechtel Hanford, Inc.

G. A. Blunt

R. A. Carlson

R. P. Henckel

M. C. Hughes

D. R. Jordan

J. H. Kessner

W. H. Price

M. R. Schwab

C. Stacey

T. M. Wintczak

J. C. Work
H4-79

H6-01

H6-01

X5-55

X2-10

H4-23

N3-05

H6-05

H4-23

H4-79

H6-03
No. of

Copies

ONSITE

2 Hanford Environmental Health Foundation

M. K. Hamilton

B5-03

J. K. Samuels

B1-61

1 ICF Kaiser Engineers Hanford

R. W. Henderson

G4-07

53 Pacific Northwest Laboratory

J. K. Ace

K3-18

T. L: Almeida (Ehlert)

P7-25

D. A. Anderson

P7-27

S. R. Bales

B. O. Barns

R. M. Bean

O. P. Bredt

D. L. Carroll

R. Cuello

J. M. Deal

R. M. Ecker

L. J. Ethridge

S. K. Fadeff

P7-72

P7-14

P8-08

P7-27

K5-20

SEQI

B1-34

SEQUIM

P7-01

W. B. Gintner

P8-08

Pา-27

M. J. Graham

K6-78

L. R. Greenwood

P7-22

C. O. Harvey

P7-22

P. C. Hays

K6-86

E. W. Hoppe

P7-22

T. Y. Hosaka

B1-40

P. M. Irving

K6-98

T. E. Jones

B1-34

C. J. Lemons

E. A. Lepel

A. G. King

K3-70

P8-08

P7-22

B. C. King

P7-72

G. S. Klinger

P7-22

D. W. Koppenaal

P7-07

K. J. Kuhl-Klinger P7-27

J. M. Latkovich P7-27

P. M. Lindsay

P7-27

M. L. Martin

T6-20

S. G. McKinley

P7-22 


\section{Distribution (cont)}

No. of

Copies

ONSITE

Pacific Northwest Laboratory (cont)

P. J. Mellinger

P7-22

R. M. Nipper

P7-27

R. W. Pennington

K3-43

J. M. Robbins

P7-22

P7-22

K1-09

P. K. Schuette

P7-27

K6-04

C. S. Sloane

B. D. Slonecker

M. L. Sours

R. L. Spinks

R. T. Steele

R. S. Strebin

R. W. Stromat

C. D. Taylor

B. L. Thomas

J. M. Tingey

M. W. Urie

T. G. Walker

L. M. Worden

Westinghouse Hanford Company

M. R. Adams

H6-30

D. R. Aichele

R. Akita

W. T. Alumkal

H. Babad

W. W. Baird

M. W. Bames

T. S. Basra

A. D. Bates

K. E. Bell

M. L. Bell

D. C. Board

D. R. Bratzel

S. L. Brey

T. H. Bushaw

R. P. Bushore

K. G. Carothers

R. J. Cash

C. A. Colvin
$\mathrm{H} 0-41$

T6-20

S7-85

57-30

T6-16

T6-16

B1-51

H4-19

T6-06

T6-16

S1-57

S7-31

T6-12

T6-30

T6-07

R1-51

S7-15

S6-20
No. of

Copies

\section{ONSITE}

Westinghouse Hanford Company (cont)

J. M. Conner

L4-75

J. R. Cooper

H4-19

T. F. Dale

T6-20

A. K. Dasgupta \$3-28

C. DeFigh-Price $\quad$ \$7-30

J. L. Deichman H4-19

L. P. Diediker T1-30

A. J. Diliberto H6-32

D. A. Dodd T6-50

M. R. Dowell · \$3-28

G. T. Dukelow \$7-15

J. A. Eacker L6-04

B. B. Emory X3-70

B. G. Erlandson H6-20

L. J. Estey T5-50

D. G. Farwick H4-16

A. L. Fishbank S5-51

D. L. Flyckt T7-38

G. D. Forehand \$7-31

L. A. Fort \$4-54

G. T. Frater \$7-30

P. B. Freeman H6-06

K. K. Giamberardini T6-06

R. R. Grabbe S3-28

K. A. Hadley R3-56

D. L. Halgren \$6-70

M. J. Hall T6-07

V. W. Hall H4-19

C. S. Haller R2-12

W. H. Hamilton N3-10

K. L. Hladek H5-33

C. S. Homi R2-12

D. G. Horton H6-06

J. L. Huckaby \$7-15

S. L. Huggins H4-23

J. E. Hyatt H4-19

T. G. Ibsen \$3-30 .

M. A. Islam H5-55

L. Jensen T6-07

J. R. Jewett T6-09

G. D. Johnson G1-19

G. D. Johnson \$7-15 


\section{Distribution (cont)}

No. of

Copies

\section{ONSITE}

Westinghouse Hanford Company (cont)

S. M. Joyce

F. M. Jungfleisch

K. H. Kary

E. J. Kosiancic

J. G. Kristofzski

G. J. LeBaron

W. D. Leggett

J. W. Lentsch

D. W. Lindsey

L. L. Lockrem

C. D. Lucas

W. L. Louk

L. P. Markel

R. P. Marshall

D. J. McCain

N. G. McDuffie

H. K. Meznarich

R. A. Meznarich

A. G. Miskho

J. R. Mobley

G. C. Mooers

P. M. Morant

J. N. Nansen

M. A. Payne

K. N. Pool

P. R. Praetorius

S. M. Price

J. R. Prilucik

R. E. Raymond

R. J. Roberts

M. R. Romsos
H4-19

T7-38

S3-28

T6-16

T6-06

S6-19

T6-07

S7-15

L6-04

S3-90

$\mathrm{X} 0-35$

T5-05

T6-16

T6-14

S7-30

S7-15

T6-16

S3-27

H6-20

H5-49

R3-85

H4-19

N1-71

S7-14

H4-23

H4-25

H6-23

T6-24

R2-54

N3-13

T3-04
No. of

Copies

ONSITE
Westinghouse Hanford Company (cont)

L. M. Sasaki R2-12

M. J. Schliebe S4-25

R. D. Schreiber R2-12

J. A. Seamans N2-04

D. A. Sebelien T6-16

P. Segall H4-19

J. P. Sloughter : T6-07

W. Smith T3-28

D. R. Speer $\quad \$ 6-65$

G. A. Stanton S7-31

C. R. Stroup H4-19

C. S. Sutter T5-12

C. D. Suydam \$3-31

R. W. Szelmeczka L4-96

L. H. Taylor H4-23

M. C. Thompson T6-14

R. R. Thompson H6-32

W. S. Thompson N3-05

D. M. Thornton T6-22

W. E. Toebe H6-10

D. A. Turner $\quad \$ 7-15$

T. B. Veneziano H6-10

O. S. Wang \$7-15

D. J. Watson X0-41

K. B. Wehner T6-50

T. E. Whelan \$1-57

J. D. Williams H6-28

W. I Winters T6-50

Central Files L8-04

OSTI (2) L8-07 
Revision 0

This page intentionally left blank. 